Discussion Papers in

Economics and Econometrics

2000

This paper is available on our website http://www/soton.ac.uk/ econweb/dp/dp00.html 


\title{
Schooling and Distortions in a Vintage Capital Model?
}

\author{
$X$ avier Mateos-Planas \\ Department of Economics \\ University of Southampton \\ High..eld SO 17 1BJ \\ Southampton, UK \\ Phone: 44-2380-595669 \\ Fax: 44-2380-593858 \\ E-M ail: fxmp@soton.ac.uk \\ May 18, 2000 \\ version 4.3 (..nal to production)
}




\begin{abstract}
This paper integrates the analysis of choices on education and on technology adoption to study international economic disparities. Two candidate explanations are considered: dixerences in distortions that axect the cost of technology adoption and dixerences in the exectiveness of schools. The implications of these two factors for dixerences in output per capita, educational attainment, and the age of technologies across-countries are assessed in a vintage capital model with technology-speci..c learning-by-doing. P redictions are obtained for a parameterized economy that matches US aggregate observations and evidence on learning. Dixerences in investment distortions produce plausible correlations only if the major role of education is to improve the ability to learn technologies. On the other hand, dixerences in school exectiveness produce plausible results only if the role of education is to provide a productive ability that is independent of learning.
\end{abstract}

? This paper is based on Chapter 3 of my PhD dissertation at Universitat Pompeu Fabra under the supervision of Ramon Marimon. My thanks go to him for useful advice as well as to J ordi Caballé, A ntonio Ciccone, J avier Díaz-J iménez, Stephen L. Parente and Gilles Saint-Paul for useful discussions and criticism. In particular, S. Parente's comments have led to substantial improvements in various parts of the paper. The paper has also bene.ted from constructive comments by two referees and the editor B oyan J ovanovic. All remaining errors are my sole responsibility. This paper was presented at the SED 1999 Meeting in Sardinia. A previous version had been circulated under the title "Education, Technology Adoption and Productivity". 


\section{Introduction}

There are persistent dixerences in income per capita across countries. A major task of economic analysis is to identify the factor or set of factors that constitute ultimate causes of these dixerences. Some recent studies -which include Parente and Prescott (1994) and J ovanovic and R ob (1998)- focus on the role of factors that axect the adoption of technologies. In the growth literature, other papers - including Lucas (1988), Mankiw, Romer and Weil (1992) and Grossman and Helpman (1991, chapter 5) - have emphasized the importance of the incentives for education. This paper integrates the analysis of both education and technology adoption in the context of a vintage-capital model with technology-sp eci..c learning-by-doing. The objective is to assess dixerent factors as explanations of observed international disparities.

The paper focuses on the role of two such factors motivated by some recent empirical studies. The..rst is dixerences in policies that axect the resource cost of capital equipment that embodies new technology. Several papers such as J ones (1994), Chari et al. (1997) and J ovanovic and Rob (1998) ..nd the price of capital to be negatively correlated with international income levels. The second factor is dixerences in the exectiveness of schools. Measures of school inputs-e.g., teacher/pupil ratio, government expenditures, number of school hours- in Barro and Lee (1997) are positively related with the level of development. The idea of school exectiveness here may also include the presence of policies and institutional distortions that axect educational outcomes for given measured inputs.

The importance of these two factors as explanations of international income dixerences is evaluated by requiring that the implied signs of the relationships between income per capita, educational attainment and the age distribution of machines be empirically consistent. More precisely, the criterion adopted in this paper is that, for a factor to qualify as a sensible explanation of disparities, the implied dixerences in output per capita must be positively related to dixerences in measures of educational attainment in population ${ }^{1}$ and negatively related to dixerences in the average age of machines ${ }^{2}$. One objective of this paper is to explore whether and when the exectiveness of education and/ or dist ortions that axect the cost of technology adoption pass this qualitative test.

The key feature of the model is the choice by agents on the length of schooling and the sequence of subsequent technology adoptions in the presence of exogenous embodied 
technological change and technology-speci... learning-by-doing. Two dixerent roles for education are considered. One assumption is the learning hypothesis, according to which education improves the ability of economic agents to learn new technol ogies. This assumption is motivated by early works on human capital by Nelson and Phelps (1966), Welch (1970) and Schultz (1975) which emphasize that education has a value in a changing environment that requires the ability to adapt to (or to learn) new technologies. The other assumption postulates that education provides a productivity advantage which is indep endent of experience. It will be referred to as the neutrality hypothesis. This assumption is found in much of the growth literature like, for example, Lucas (1988), Grosman and Helpman (1991,chapter 5), and Bils and Klenow (1998).

Balanced-growth output comparisons are conducted for economies that dixer in school exectiveness and investment distortions. The benchmark economy roughly matches US aggregate observations and evidence on learning processes. The ..ndings from the numerical exercise are as follows. Under the learning hypothesis, the model predicts positive correlations between per capita output, education and a lower machine age only when economies dixer in adoption costs. In this case, the response of the pattern of technology adoption is key to the predicted exects. Under the neutrality view, only variation in school exectiveness predicts the right signs for these correlations. In this case, the decisions on technol ogy adoption play a mere supportive role. The results are informative as to mechanisms that may be important ingredients in a theory of international disparities.

In that the interaction between education and technology is analyzed to explain economic dixerences, this paper relates to a body of literature that includes Stokey (1991), Ciccone (1996), Keller (1996), Restuccia (1997) and J ovanovic (1998). In the present paper, the nature of this interaction is as follows. How much education individuals acquire depends on the expected pace of adoption of new technologies they will have to learn and operate after their education; on its part, the pattern of adoption of new technologies is in $\ddagger$ uenced by the level of educational skills of the workers and managers that have to learn and operate those technologies. Here this interaction can be analyzed because the problem of adoption/replacement of technologies over time with technology-speci..c learning has been explicitly worked out. This dixers from the other papers cited that do not analyze this type of problem and cannot, therefore, analyze this connection. They assume, rather than derive, some form of technology-skill complementarity that brings automatically to- 
gether the skilled agents and the advanced technologies. In this sense, one contribution of the present analysis is to provide a model with stronger micro-foundations that allows to examine how the relation between education and technology may be altered by policies and the role of education.

The model al so shares features with recent analyses of the choice of replacement/ adoption of technologies in dynamic settings in Parente (1994), Cooley et al. (1997), Greenwood and Yorukoglu (1996), K lenow (1998), J ovanovic and Rob (1998) and Parente (1999). In Parente (1994) and Parente (1999), learning is not completely technology-speci..c and education is treated parametrically. J ovanovic and Rob (1998) do not consider learning-by-doing nor education but endogenize the creation of new technologies. In K lenow (1998) there is no education either but there is variable labor intensity in production which axects learningby-doing; here the technology is of ..xed-coet cients and learning depends on the passage of time. Cooley et al. (1997) introduce education, but it axects the creation of technologies rather than their adoption. In G reenwood and Yorukoglu (1996) ..rms hire skilled workers to accelerate learning, which resembles the learning assumption made here.

Of all these papers, only J ovanovic and R ob (1998) and Parente (1999) analyze sources of long-run disparities in international income levels. B oth papers quantify the level exects of investment distortions which are found to be small, although somewhat larger in Parente (1999) where adoption of below-frontier technologies is allowed. While introducing the endogenous response of education, the present paper does not improve the quantitative implications found in these other papers. Parente (1999) also explores the level exects of parameters that are associated with the assumptions on education made in the present paper.

The rest of the paper is organized as follows. Section 2 describes the model. Section 3 analyzes the optimal choices on technology adoption and education. Section 4 de. nes and characterizes bal anced-growth equilibria. Section 5 calibrates the model and rep orts steadystate comparisons associated with dixerences in adoption costs and school exectiveness under both assumptions on the role of education. Conclusions and remarks about directions for future research in section 6 conclude the paper. 


\section{The M odel}

Demographics

The economy is populated by a continuum of overlapping generations of agents. Each agent faces a constant probability of death per unit of time, p, which is independent of age. The size of population is normalized to one by letting the size of each new cohort be equal to $p$. Then pei $p\left(t_{i} i\right)$ is the measure of agents born at $i$ that are alive at time $t$. In the ..rst part of his life, an agent goes to school for a length of time s. In the remaining part of his life, he produces output by operating a ..rm.

\section{Output technology}

There is a single homogeneous good that can be used for consumption or investment. Each ..rm produces output using one machine. The fow of output of a ..rm depends on the quality of the machine in use, on the agent's technology-speci..c expertise, and on the agent's general skill. The quality of the machine is given by the technology embodied in it and I index technologies over the positive real line by a. Expertise in a technology, q, can take on only two values, 1 and \pm with $\pm>1$. General skill is represented by a positivereal number $h$. Output of a ..rm that operates a machine of quality a with technology-speci..c expertise $q$ and general skill $h$ is

$$
\text { h } \$ q \pitchfork a ;
$$

with $q 2$ fl; $\pm g$ and $a ; h 2 R_{+}$.

At any instant of time, a ..rm may either switch to a more advanced technology or continue to use the present one. I call technology adoption the decision to operate a new technology by replacing the current machine with another of dixerent quality.

If the ..rm's experience in the use of its current technology is shorter than a period of length ${ }^{1}$, its level of expertise in this technology is 1 . Thereafter, its level of expertise in this technology increases to \pm Figure 1 depicts the typical path of technology-speci..c expertise.

\section{INSERT FIGURE 1 ABOUT HERE}

This learning-by-doing is technology-speci..c. Thus if the ..rm decides to switch tech- 
nologies, no part of the expertise in the previous technology can be carried over to the new one $^{3}$.

The upper bound on the technologies that can be used by any ..rm at time t is denoted by $A(t)$. This frontier technology grows at a constant and exogenous rate ${ }^{\circ}$ over time.

Switching to a technology a requires an expenditure of $1 / 4 \$ a$ units of output in the machine embodying that technology. The parameter $1 / 4$ is a policy parameter that axects the resource cost of a machine.

\section{E ducation}

The length of time, ${ }^{1}$, that it takes for a ..rm to accumulate expertise in a technology is determined by the schooling of the agent that runs it. The years of schooling of an agent is denoted by S. The value of ${ }^{1}$ depends negatively on the time an agent spends in school. In particular, ${ }^{1}$ is assumed to be a non-increasing function of $s^{1}(s)$. More speci..cally,

$$
1=1(\mathrm{~s})^{\prime}{ }^{1} \mathrm{e}^{\mathrm{i}, \mathrm{s}}
$$

with ${ }^{1}{ }_{0}$ and, being non-negative constants. This view of schooling is referred to as the learning hypothesis.

Schooling can also axect an agent's general level of skill, h. I assume h to be a nondecreasing function, $h(s)$, of $s$. Speci..cally,

$$
h=h(s)^{\prime} h_{0} s^{-}
$$

with $h_{0}$ and - being non-negative constants. This view of schooling is referred to as the neutrality hypothesis 4 .

I will interpret, and ${ }^{-}$as measuring the exectiveness of individual time spent in the class-room. This school exectiveness may certainly depend on the quality and quantity of educational inputs other than individual time. But it may also include policy distortions and institutional factors that spur or hamper the acquisition of the relevant skills. For instance, national educational programs that emphasize contents not directly usable in production will have a smaller ${ }^{-}$; schemes that emphasize information acquisition rather than analytical skills and critical awareness will be associated with smaller.. 
P references, markets and the distribution of wealth

A $n$ agent belonging to cohort $i$ has preferences de..ned over life-time streams of consumption. Because of lifetime uncertainty, utility is evaluated in expected terms and is represented by

$$
E{\frac{1}{1 i^{3 / 4}}}_{i}^{Z_{i+T}} e^{\left.i^{1 / k t_{i}} i\right)} c(t ; i)^{1_{i} 3 / 4 d t} \text {; }
$$

where $T$ is time-until-death, $\mathrm{c}(\mathrm{t} ; i)$ is the fow of consumption to an agent of cohort $i$ at time $t, 1 / 2$ is the subjective time-discount rate, and $3 / 4$ is the relative rate of risk aversion. Since the probability of death, $\mathrm{p}$, is constant, $\mathrm{T}$ is an exponential random variable with density pei ${ }^{\mathrm{PT}}$ and utility can be rewritten as

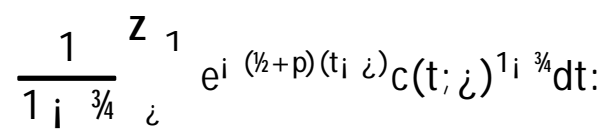

There is a perfect capital market where agents can borrow and lend. There is a market for insurance where insurance companies make premium payments to the living in exchange for receipt of their assets in the event they die. Free-entry in this market implies that the insurance premium equals $p$ per unit of time. When an agent dies, the ..rm she is operating is dissolved and there is no market for discontinued ..rms.

The agent is assumed to have a wealth given by the life-time present value of percapita output minus adoption costs. The correct interpretation is to think of the agent as belonging to an extended family where all members of all ages share overall family output at every point in time 5 .

\section{Optimal Individual Choices}

The objective of an agent is to maximize the utility function in equation (4) taking prices as given. Since I focus on balanced-growth equilibria, I consider a constant interest rate r. This problem has two parts. The ..rst part is that the agent maximizes the present life-time value of the ..rm he operates. This choices maximizes the agent's wealth since it maximizes its contribution to the present value of net output per capita. Towards this end, an agent of cohort $i$ has two choices to make. First, he chooses how long to attend school, S. Second, after school has been completed, the agent decides which technologies to use at every instant over his productive life. The choices that maximize a ..rm's present value can 
be found in two steps. First, given a choice $s$, and hence ${ }^{1}$ and $h$, it is possible to solve for the optimal pattern of technology adoption. Having obtained the optimal technology adoption decisions as a function of $s$, it is possible to ...nd the optimal schooling level that maximizes the present value of the ..rm. The second part of the agent's problem is that the agent, as a consumer, chooses a path for consumption that maximizes utility subject to the constraint that the discounted present value of consumption does not exceed his wealth.

In this section, I characterize the optimal technology adoption and schooling decisions of an agent born at time $i$. Section 3.1 shows that optimal technology adoption results in a sequence of evenly spaced dates at which the ..rm switches to the frontier technology and stays there until the next upgrade. The exect of parameters on the frequency of technology upgrades is analyzed. The optimal schooling choice can then be determined. Section 3.2 analyzes this decision and highlights the mechanisms underlying the response of schooling and technology adoption to changes in investment distortions and school ex ect iveness under two views about the role of education.

\subsection{Technology Adoption}

I begin by assuming that the agent has already chosen $\mathrm{s}$ and so the values of ${ }^{1}$ and $\mathrm{h}$ have already been determined. B efore describing this problem formally I de. ne a feasible adoption plan. Exposition is simpli..ed by noting that the assumption $1 / 4>0$ rules out the optimality of plans characterized by continuous switching of technologies. Thus, without any loss, I ignore this possibility in the following de..nition.

De.nition 1: Given the path for the frontier technology $A(t)$, a feasible adoption plan for an agent born at time $i$ with schooling $s$ is de..ned by:

(i) A sequence $f x_{j} g$ representing the dates at which each $j$ th adoption occurs for $j=1 ; 2 ;:: ; j$, such that $x_{j}, i+s$ and $x_{j+1}>x_{j}$. The number of adoptions, J , may be either a positive integer -in which case I adopt the convention that $x_{\mathrm{J}+1}=+1$ - or in..nity.

(ii) A path for technologies represented by a function $a(t ; i)$ de..ned for $t$, $i+\mathrm{s}$ such that $\mathrm{a}(\mathrm{t} ; \mathrm{i}) \quad \mathrm{A}(\mathrm{t})$, and $\mathrm{a}(\mathrm{t} ; \mathrm{i})$ constant for $\mathrm{t} 2\left(\mathrm{x}_{\mathrm{j}} ; \mathrm{x}_{\mathrm{j}+1}\right)$ all $\mathrm{j}=1 ; 2 ;:: ; j$. 
The technology in (1) and the structure of learning imply that a feasible adoption plan generates the following path for the ..rm's output, $y(t ; i)$,

$$
y(t ; i)=\begin{array}{ll}
\stackrel{8}{\gtrless} h \phi a\left(x_{j} ; i\right) & t 2\left[x_{j} ; \operatorname{minf}_{j+1} ; x_{j}+{ }^{1} g\right) \\
? h \phi \pm \phi a\left(x_{j} ; i\right) & t 2\left[\operatorname{minf}_{j+1} ; x_{j}+{ }^{1} g ; x_{j+1}\right)
\end{array}
$$

Now the problem of a ..rm consists of maximizing the present value of output net of adoption costs by choosing a feasible adoption plan or making no adoption at all. To characterize the solution it is convenient to set up the objective more formally.

The existence of an insurance premium implies that the agent discounts values at the rate $r+p$. De.ne by $m_{j}$ the length of the period over which the $j$ th technology is operated in a feasible adoption plan, i.e. $m_{j}{ }^{\prime} x_{j+1} i x_{j}$. The present discounted value as of date $x_{j}$ of net output accruing between $x_{j}$ and $x_{j+1}$ can then be expressed as $h \phi a\left(x_{j} ; i\right) \notin W\left(m_{j}\right)$ where

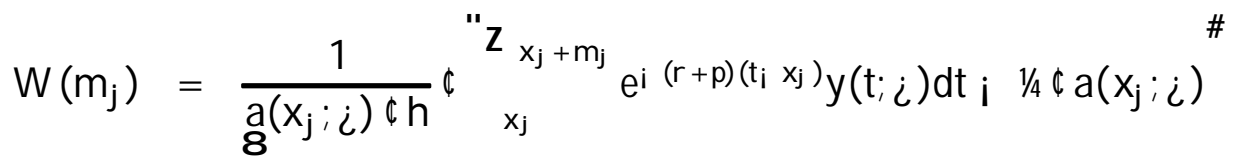

$$
\begin{aligned}
& =\begin{array}{ll}
\gtrless \frac{1}{r+p}\left[1 ; e^{i(r+p) m_{j}}\right] i \frac{1 / 4}{h} & m_{j}<1 \\
>\frac{1}{r+p}[1+( \pm i & \left.1) e^{i(r+p)^{1}} i \quad \pm e^{i(r+p) m_{j}}\right] i^{\frac{1 / 4}{h}} m_{j},{ }^{1}
\end{array}
\end{aligned}
$$

is an increasing, bounded, continuous and piece-wise dixerentiable function of $m_{j}$. Thus the present value as of date $i+s$ associated with a feasible adoption plan can now be expressed as the following discounted sum of net values accruing from the adoption and use of dixerent technologies,

$$
h \underset{j=1}{x} W\left(x_{j+1} i \quad x_{j}\right) \phi a\left(x_{j} ; i\right) \phi e^{i(r+p)\left(x_{j} i(i+s)\right)}
$$

The problem of the ..rm is to choose the adoption plan that maximizes the value of expression (7) if it is positive or else remain inactive and produce zero. I will characterize the solution when the size of investment distortions is not too large and the frontier technology does not advance too fast. This is the case when the two following conditions hold.

$$
\begin{aligned}
& \text { C1: } \lim _{m !+1} W(m)=\left(1+( \pm i \quad 1) \exp \left(i(r+p)^{1}\right)\right)=(r+p) i 1 / 4 h>0 \\
& \text { C2: } r+p_{i}{ }^{\circ}>0 .
\end{aligned}
$$


A ssuming $\mathrm{C} 1$ rules out inactivity as an optimal choice and then $\mathrm{C} 2$ restricts the class of feasible adoption plans that are optimal. Proposition 1 states this result more precisel ${ }^{6}$.

Proposition 1: If conditions $\mathrm{C} 1$ and $\mathrm{C} 2$ hold then:

a. An optimal choice involves a feasible adoption plan with adoption of the frontier technology, i.e. $a\left(x_{j} ; i\right)=A\left(x_{j}\right)$ all $j=1 ; 2 ;:: ; j$.

b. In an optimal feasible adoption plan the ..rst adoption occurs at $i+s$, i.e. $x_{1}=i+s$.

Since the technology to be adopted when upgrading is always the frontier, solving for the optimal timing of adoptions will complete the characterization of the adoption choice. By proposition 1 the objective in (7) can be cast in recursive form. This leads to the following result.

Proposition 2: Assume $\mathrm{C} 1$ and $\mathrm{C} 2$ hold. In an optimal adoption plan $\mathrm{x}_{\mathrm{j}+1} \mathrm{i}$ $x_{j}=m$ all $j=1 ; 2 ;: . ; j$ j where $m 2 R+$ solves,

$$
V=\operatorname{maxf}_{m} W(m)+e^{i\left(r+p_{i}{ }^{\circ}\right) m} V g
$$

and the resulting $\mathrm{V}$ is such that

$$
A(\Sigma+s) \phi h \& V
$$

is the value of the expression in (7) in an optimal plan.

This proposition says that optimal upgrades occur at a constant frequency because the ..rm faces the very same problem (8) any time it has to decide for how long to hold out a new machine. Still, the number of adoptions, J, can be either 1 [if $m=+1$ ] or in..nity [if $m<+1$ ]. The solution also delivers the value $V$ which is $\left.W(m) \neq 1 ; \quad \exp \left(i\left(r+p_{i}{ }^{\circ}\right) m\right)\right)$ when evaluated at the optimal $\mathrm{m}$. Then, the maximized value of the objective (7) can be calculated as (9).

I now proceed to characterize the solution to problem (8). This problem is a onestage optimization program. The only diф culty arises because the assumption of learning as a step function creates a discontinuity in the derivative of the objective at $m=1$. 
Nonetheless, theoptimal $m$ can still be characterized as a solution to a ..rst-order condition. Proposition 3 establishes this result as well as the procedure to ..nd the solution.

Proposition 3: Assume $\mathrm{C} 1$ and $\mathrm{C} 2$ hold. Then:

a. A solution to (8) implies $m<+1$ and must satisfy

$$
\left.\Phi(m)^{\prime} W 9 m\right) i\left(r+p i^{\circ}\right) \frac{e^{i\left(r+p_{i}{ }^{\circ}\right) m}}{1 i e^{i\left(r+p i^{\circ}\right) m}} W(m)=0:
$$

b. If $\lim _{1} \phi(m)>0$ then the solution to (8) is the unique root of (10) with $m>1$. If $\lim _{1_{i}} \phi(m)<0$ and $\lim _{1+} \phi(m)<0$ then the solution to (8) is the unique root of (10) with $m<1$. If $\lim _{1 i} \$(m)<0$ and $\lim _{1+} \phi(m)>0$ then there are two roots of $(10)$, one on each side of ${ }^{1}$. The solution to problem (8) is the one root that yields the highest value of $W(m)=\left(1 ; \exp \left(i\left(r+p_{i}{ }^{\circ}\right) m\right)\right)$.

According to this proposition, solving (8) only requires to ..nd the values of $m$ that solve the .r.st-order condition (10). The procedure in part $b$ indicates that there are at most two such values and exactly determines when the solution is to be found for values that are smaller than ${ }^{1}$, larger than ${ }^{1}$ or both. To understand the statements, it helps to depict $\phi(m)$ as a piece-wise concave function that starts positive, eventually becomes monotonically decreasing and exhibits a positiveright jump at ${ }^{1}$ whereyet the sloperemains continuous.

I will now use the ..rst order condition (10) to shed some light on the determinants of the time between adoptions $\mathrm{m}$. P roposition $3 \mathrm{~b}$ recognizes that a change in parameters may induce a discontinuous response of $m$ if it implies a move from a plan where learning occurs [i.e. $m>^{1}$ ] to a plan where more frequent upgrades imply that learning does not occur [i.e. $m<{ }^{1}$ ], or the other way around. This notwithstanding, here I will focus on changes that produce a local response when $m>^{1}$. It helps intuition to use (6) to rearrange (10) as,

$$
\pm=\left(r+p_{i}{ }^{\circ}\right) \frac{e^{\circ m}}{1 i e^{i\left(r+p_{i}^{\circ}\right) m}} W(m)
$$

The two-sides of this equation contain, respectively, the normalized values for the marginal bene.t and marginal cost of $\mathrm{m}$. As I am looking at a situation where $m>^{1}$, the marginal 
bene.t of $\mathrm{m}$ consists of the current $\neq$ ow of normalized output on the current technology, \pm The marginal cost consists of the discounted foregone present value that would arise on switching to a new machine whose quality exceeds the current one's by a factor $\exp \left({ }^{\circ} \mathrm{m}\right)$. It is optimal to pick $m$ so that these two values are equalized.

For the purposes of this paper, it is important to understand how the pattern of technology adoption is axected by investment distortions, $1 / 4$ and education, $h$ and ${ }^{1}$. These parameters show up within $W(m)$ in condition (11). Furthermore, by (6), the role of $h$ and $1 / 4$ for technology adoption is entirely captured through the ratio $1 / 4 h$. In other words, general skill dampens the presence of investment distortions. One can ..gure out the exect of slower learning-by-doing, lower general skill or higher investment distortions on optimal $\mathrm{m}$. By reducing $W(\mathrm{~m})$, both larger ${ }^{1}$ and larger $1 / 4 \mathrm{~h}$ produce a downward shift of the marginal cost leading to larger $m$, which implies less frequent technology adoptions.

\subsection{Schooling Choice}

The length of schooling attendance, $s$, is decided optimally taking into account its exects on the value of the ..rm which, in turn, depends on the response of technology adoption choices. To analyze this problem, it is useful to represent explicitly the dependence of the value of the ..rm on ${ }^{1}$ and $1 / 4 h$. Let $V(1,1 / 4 h)$ denote the value that solves (8) as a function of these two variables. Then, by (9) in proposition 2 , the value of the ...rm can be written as $A(i+s)$ th $\phi V(1 ; 1 / 4 h)$. The agent's goal is to maximize the present discounted value of this expression as of date $i$. The technology of education described in (2) and (3) and the assumption that $A(t)$ grows at rate ${ }^{\circ}$ therefore imply that the agent solves

$$
\begin{array}{ll} 
& \max _{\mathrm{s}, 0} \mathrm{e}^{\mathrm{i}\left(\mathrm{r}+\mathrm{p}{ }^{\circ}\right) \mathrm{s}} \mathrm{h}(\mathrm{s}) \mathrm{V}\left({ }^{1}(\mathrm{~s}) ; 1 / \mathrm{l} / \mathrm{h}(\mathrm{s})\right) \\
\mathrm{s}: \mathrm{t}: \quad{ }^{1}(\mathrm{~s})={ }_{0} \mathrm{e}^{\mathrm{i}, \mathrm{s}} \\
\mathrm{h}(\mathrm{s})=\mathrm{h}_{0} \mathrm{~s}^{-}
\end{array}
$$

Since proposition $3 \mathrm{implies}$ that $\mathrm{m}$ in program (8) can be bounded, application of the maximum principle implies that the objective of this program is continuous in $\mathrm{s}$. Without an upper bound on $\mathrm{s}$, existence of a solution cannot be generally established though.

$\mathrm{N}$ ext, the specialized problems that arise under two speci..c assumptions on education 
are considered. The analysis will focus on each case separately to draw the implications of changes in investment distortions, $1 / 4$ and measures of the exectiveness of schooling, , and - , for the optimal level of schooling s that solves (12).

\subsubsection{The Learning Hypothesis}

In this case, the parameter ${ }^{-}$is assumed to be zero so that $\mathrm{h}$ is not axected by $\mathrm{s}$. W ithout loss of generality, I normalize $h=1$ by setting $h_{0}=1$. Assume that a solution to (12) is interior, implies $\mathrm{m}>^{1}$ and is characterized by a ..rst-order condition which must read,

$$
\frac{d V\left({ }^{1}(s) ; 1 / / 4 h\right)}{d^{1}} 19(s)=\left(r+p_{i}{ }^{\circ}\right) V(1(s) ; 1 / 4 h)
$$

which equates marginal bene..t (left) and marginal cost (right) of $\mathrm{s}^{7}$.

Now, consider the exect of an increase in $1 / 4$ on this equation. The marginal cost on the right, $V\left({ }^{1} ; 1 / 4 h\right)$, is reduced which tends to dictate higher schooling $S$. This is an opportunity-cost exect. On the other hand, $m$ goes up so adoptions of technology become less frequent. This reduces the marginal bene.tt of education on the left-hand side of (13): less frequent adoptions make the ability to learn new technologies provided by education less valuable. This tends to reduce the optimal time spent at school. Thus investment distortions may have a negative impact on educational attainment only because of this latter exect.

On its part, a lower quality of education, , also produces exects on both sides of (13). A gain, the opportunity cost on the right-hand side is reduced which works in favor of longer schooling. On the left-hand side of (13), the marginal bene..t falls as $\operatorname{larger}^{1}(\mathrm{~s})$ as well as the consequent rise of $m$ reduce the marginal gain of speeding up learning through schooling (the $; d V=d^{1}$ term). This tends to reduce schooling. Finally, there is the exect from the direct impact on ${ }^{10}$ that may have either sign on the marginal bene.. $t^{8}$.

\subsubsection{The Neutrality Hypothesis}

In this case, the parameter, is assumed to be zero so that ${ }^{1}$ is not axected by s. As before, assume that a solution to (12) is interior, implies $m>^{1}$ and is characterized by a 
..rst-order condition which must read,

$$
i \frac{d V(1 ; 1 / 4 h(s))}{d(1 / 4 h(s))} \frac{h 9 / s)}{h(s)}+h 9(s) V(1 ; 1 / 4 h(s))=\left(r+p i^{0}\right) h(s) V(1 ; 1 / 4 h(s))
$$

which equates marginal bene.t. (left) and marginal cost (right) of $s$. The marginal bene.t includes the increase in disembodied productivity $h$ as well as the exect on the value of the ..rm through the term $1 / 4 \mathrm{~h}^{9}$.

Consider a rise in $1 / 4$ Ignoring for the moment the response of the ..rst term on the left-hand side, the exect on $\mathrm{V}\left({ }^{1} ; 1 / \mathrm{H} h(\mathrm{~s})\right)$ shifts both marginal cost and marginal bene.t downwards, but the absolute shifts of marginal cost is bigger which tends to increase $s^{10}$. But the ..rst component of the marginal bene..t will also change In particular, the fact that $\mathrm{m}$ increases, and hence adoptions become less frequent, brings about a reduction of the marginal bene.t of reducing the adoption cost term, 1/ah, through education. This tends to dictate lower education.

A reduction in the exectiveness of schools also reduces the second term on the marginal bene.t side as well as the marginal cost. The ..rst term of the marginal bene.t will also decrease except for the possibility that the rise in the marginal return of education due to larger $1 / 4 h$ is quantitatively substantial.

\section{Equilibrium}

The exercises conducted in the previous section suggest that when the choice of technology is endogenized, the response of schooling to changes in various parameters cannot generally be determined. I now proceed with the characterization of a balanced-growth path equilibrium. I will then be able to pin down reasonable parameters values and therefore obtain predictions for dixerences in output per capita, educational attainment and the age of capital produced by dixerences in the level of investment distortions and the exectiveness of schools.

I study balanced-growth equilibrium paths al ong which all aggregate quantities grow at a constant rate and the interest rate is constant. I de.ne such an equilibrium as follows.

De..nition 2. Given $3 / 4 \frac{1}{7} p, \pm{ }^{\circ}, 1 / 4^{1}(:), h(:)$, and a distribution of wealth $Z(i)$, a competitive balanced growth equilibrium is a constant $m$ denoting the 
spacing between adoptions, a constant level of education $\mathrm{s}$, a distribution of output per ..rm $y(t ; i)$, a path for per-capita output $y(t)$, a distribution of individual consumption $c(t ; i)$, a path for per-capita consumption $c(t)$, and a constant interest rate $r$, such that:

1. Taking $r, s,{ }^{1}(s)$ and $h(s)$ as given, $y(t ; i)$ is determined by (5) for an optimal technology adoption plan by a ..rm of vintage $i+s$ characterized in propositions 1 through 3 , with $\mathrm{m}$ being the optimal length of time between adoptions.

2. Taking $r$ as given, $s$ is optimal in that it solves (12).

3. Given $r, c(t ; i)$ maximizes utility of the agent of cohort $i$ in (4) subject to the constraint that the present value of consumption cannot exceed his wealth $Z(i)$,

$$
\mathrm{Z}_{i} \mathrm{C}(\mathrm{t} ; i) \mathrm{e}^{\mathrm{i}(\mathrm{r}+\mathrm{p})\left(\mathrm{t}_{\mathrm{i}} i\right)} \mathrm{dt}=\mathrm{Z}(i):
$$

4. M arket clearing and aggregate consistency. A ggregate consumption equals aggregate output minus investment ${ }^{11}$,

$$
c(t)=y(t) i \frac{\text { pei } p s}{1 ; \text { ei } p m} 1 / A(t)
$$

with

$$
c(t)={ }_{i 1}^{Z_{t}} p e^{i p\left(t_{i} i\right)} c(t ; i) d i
$$

and

$$
y(t)={ }_{i 1}^{z_{t i s}} p e^{i p\left(t_{i} i\right)} y(t ; i) d i:
$$

5. $c(t)$ and $y(t)$ grow at a constant rate.

6. Conditions $\mathrm{C} 1$ and $\mathrm{C} 2$ hold.

Points 1 and 2 in the de. nition require that agents behave optimally. By point 6 and the results in section 3 , the individual path of output then results from writing (5) for a feasible plan with $x_{j+1} i x_{j}=m$ all $j$ and $a\left(x_{j} ; i\right)=A\left(x_{j}\right)$. This yields, 


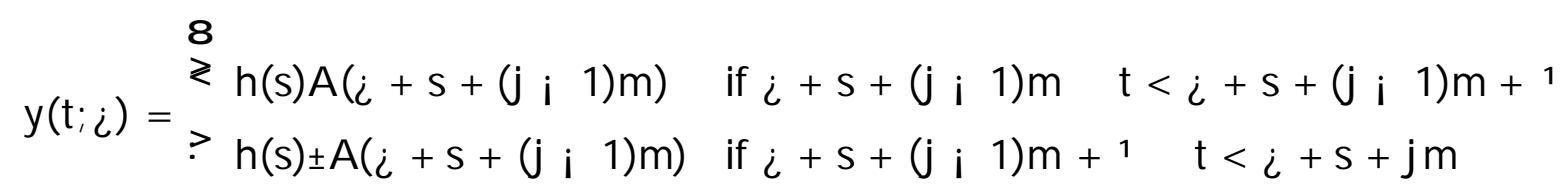

where $\mathrm{m}$ and s solve (8) and (12) respectively. The formula for aggregate output in point 4, which takes into account the age structure of population, can then be developed to obtain

$$
\begin{aligned}
y(t) & =x_{j=1}^{Z_{t_{i} s_{i}(j i 1) m}} p e^{i p\left(t_{i} i\right)} y\left(t_{i} i\right) d i \\
& =A(t) \frac{p}{0} \frac{e^{i p s}}{p 1 e^{i p m}} R(m ; s)
\end{aligned}
$$

with

$$
R(m ; s)=\begin{array}{ll}
\stackrel{8}{\gtrless} 1 ; i e^{i\left({ }^{\circ}+p\right) m} & m<1(s) \\
>\left(1 ; \quad e^{\left.i^{(0}+p\right)^{1}(s)}\right)+\#\left(e^{\left.i^{(0}+p\right)^{1}(s)} i e^{i\left({ }^{\circ}+p\right) m}\right) & m>^{1}(s)
\end{array}
$$

Hence, aggregate output grows at the same rate as the frontier technology ${ }^{\circ}$ and, by the market-clearing condition (15) in point 4, so does aggregate consumption and, hence, point 5 in the de..nition holds. It remains to ..nd for which interest rate $r$, if any, percapita consumption, $c(t)$, calculated by aggregation of individual consumption, $c(t ; i)$, is consistent with the market clearing condition in (15). With the preferences described by (4) and the assumption of free borrowing and lending, point 3 implies that individual consumption, $\mathrm{c}(\mathrm{t} ; \mathrm{i})$, grows at a constant rate ${ }_{\mathrm{c}}$ with

$$
{ }^{\circ}=\frac{r_{i} 1 / 2}{3 / 4}
$$

To add up consumption of the dixerent agents, it is necessary to be speci..c about the distribution of wealth across cohorts $Z(i)$. The assumption of the model is that $Z(i)$ is the present value of net output per capita over the agent's lifetime,

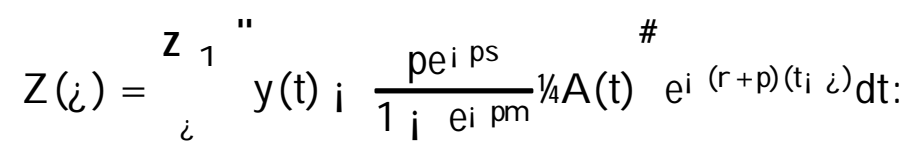

U sing the intertemporal budget constraint in point 3 and constant growth rates ${ }^{\circ}{ }_{c}$ and ${ }^{\circ}$ for individual consumption and aggregate net output respectively, the condition for aggregate 
consumption in point 4 can be rewritten as

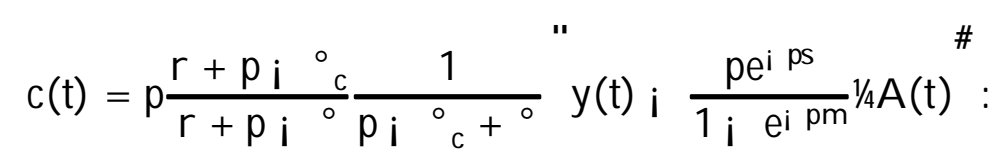

In a balanced growth equilibrium, the market clearing condition (15) must be satis..ed for consumption as given in (19) and growth of individual consumption as in (17). Simple inspection indicates this holds for $r={ }^{\circ}$ and for ${ }^{\circ}{ }_{C}={ }^{\circ}$. This leads to the following proposition.

Proposition 4: Assume $Z(i)$ is given by (18) and conditions $C 1$ and $C 2$ hold for $r={ }^{\circ}$ and $r=3 / 4+1 / 2$ Then the economy has two balanced growth equilibria. The type-1 equilibrium has $r=3 / 4+1 / 2$ and ${ }^{\circ}{ }_{C}={ }^{0}$. The type 2 equilibrium has $r={ }^{\circ}$ and ${ }^{\circ}{ }_{C}=\left(r_{i}{ }^{1} / A=3 / 4\right.$

To develop the intuition, notice that on a balanced growth equilibrium individual consumption must grow at a constant rate. There are dixerent such paths that satisfy the intertemporal budget constraint and market clearing. In the type-1 equilibrium, individual consumption is growing at the same rate as per-capita net output at every time. In this case, all agents of all ages have the same consumption level equal to per-capita net output. A nother path consistent with market clearing is associated with the type-2 equilibrium. If, as I will assume later, $3 / 4,1$, then consumption declines relative to net individual income over the life-cycle so that young agents borrow and old agents lend. A complete analysis of the stability properties of the two equilibria is beyond the scope of this paper.

\section{Numerical Experiments}

I will analyze numerically the exect of dixerences in investment distortions and the exectiveness of schools on the two types of balanced growth equilibria. To this purpose, I need to assign values to the parameters of the model. To impose some discipline, in section 5.1 parameters values will be selected so that the equilibrium of the benchmark economy mimics observed features of the US economy. Then, in section 5.2, I will be able to compare balanced-growth path equilibria of dixerent economies. Solving for an equilibrium involves, .rst, calculating the interest rate as in proposition 4 , second, compute optimal adoptions 
and schooling by solving (8) and (12), and, ..nally, compute output in (16) and a measure of the average age of machines in operation ${ }^{12}$. Section 5.3 considers modi..cations to the basic model. The ..ndings will be discussed in section 5.4 .

\subsection{Calibration}

In order to be ableto match observations on the interest rate and output growth, thetype-1 equilibrium is chosen to select the benchmark parameters. The parameters of the model are: ${ }^{0}, p, 1 / 23 / 4 \pm 1 / 4 h_{0},{ }^{-}, 1{ }_{0}$ and, . I will calibrate these parameters under two dixerent assumptions about the role of education. These two assumptions are the learning and the neutrality hypotheses discussed in section 3. For each of the two calibrations, I use the following procedure.

1. Set calibration targets for long-run growth rate of output per-capita, risk-free interest rate, life-expectancy, spœd of learning-by-doing, progress ratio, investment/ output ratio, years of schooling and general skill.

2. Choose ${ }^{0}, 3 / 4$ and $1 / 250$ that, using proposition 4 , the targets for the growth rate of output per capita and the risk-free interest rate in step 1 are matched. Choose $p$ so that $1 \Rightarrow p$ matches the target for life-expectancy in 1 . Choose \pm consistent with the progress ratio in 1.

3. Fix values of $s$ and $h$ consistent with the targets in step 1 .

4. Pick a value for $1 / 4$

5. Pick a value for ${ }^{1}$.

6. Compute the optimal adoption length $\mathrm{m}$.

7. Check outcome is consistent with target for speed of learning in 1. If not, update ${ }^{1}$ and go back to 6 .

8. Check outcome is consistent with target for investment/ output ratio in 1 . If not, update $1 / 4$ and go back to 5 . 
9. Choose parameters $h_{0},-{ }^{1}{ }_{0}$ and, so that the optimal choice of schooling $s$ and $h(s)$ matches the values $s$ and $h$..xed in step 3 , and ${ }^{1}(s)$ matches the ${ }^{1}$ found as output of steps 4-8.

I will now describe the choice of values for the targets in step 1. I use an average growth rate of output per capita of 2 per cent and a risk-free interest rate of 4.5 per cent. Life in the model starts after early childhood so life-expectancy is set at 66.66 years, which is in line with ..gures in Barro and Lee (1994). Following the choice in K lenow (1998), the progressratio is ..xed a priori to 2 . Studies on learning-by-doing indicate that progress ratios vary widely across plants, sectors and industries. The choice made here can be justi..ed as a rough average of various pieces of evidence ${ }^{13}$. To measure the speed of learning I draw on evidence in Bahk and Gort (1993) and Bessen (1997) that learning is exhausted after approximately 5 years. For the investment/ output ratio I use 7.3 per cent share of equipment investment in GNP from NIPA. Given that the model excludes investment on the intensive margin, I take as satisfactory an investment/ output ratio around 6.4 per cent. The target ..gure for educational attainment is 10 years. Average education in population in US over age 25 was 9.36 years in 1965 and 11.78 in 1985 . Finally, the value of general skill is normalized to 1 .

In step 7, I want to verify if the implied choices are consistent with the target set for the speed of learning in step 1 . Since in the model learning is a step function, to use that evidence an approximation must be done. Consider a parameterized version of the learning-curve used in Parente (1994) which expresses output as a function of time, $2 i(2 ; 1) \exp (i \mathrm{i}: 4565 t)$. This continuous-learning curve involves the target progress ratio of 2 and is roughly consistent with the evidence in that, after 5 years, learning involves growth less than 0.05 per cent ${ }^{14}$. I will move on to step 8 when ${ }^{1}$ and $1 / 4$ are such that the model's learning process is equivalent to this continuous learning process in the sense that, for the model's optimal $m$, the two processes yiel $d$ the same value for the ..rm ${ }^{15}$.

$F$ inally, in step 9 the computation of the optimal choice of $s$ is done on a discrete grid. In all the calculations, the objective in problem (12) is well de.ned with the possibility (under the learning hypothesis) of a local maximum at $s=0$. Table 1 summarizes the choices of parameters. 


\subsection{Balanced-G rowth Comparisons}

This section considers the balanced-growth exect of increases in the size of investment distortions, $1 / 4$ and decreases in school exectiveness, , or ${ }^{-}$, relative to the benchmark economy. Figures on educational at tainment $s$, relative income per capita $y=y$ us, and the average age of machines are reported. The length of technology adoptions, m, is also reported. The fact that the interest rate remains unaxected in either type of equilibrium means that the analysis in section 3 carries over to interpret the results.

\subsubsection{Type-1 equilibrium}

Table 2 below reports ..gures associated with various values of $1 / 4$ under the two assumptions about the role of education for type-1 equilibria. The ...st row corresponds to the benchmark economies.

INSERT TABLE 2 ABOUT HERE

Under the learning hypothesis, the return to education is closely linked to the pattern of technology adoptions. As discussed in section 3.2.1, higher size of distortions that axect the cost of equipment tend to reduce the frequency of technology updates and the opp ortunities for learning. Thus education that improves learning ability is less val uable and agents reduce the period of time spent in school. In the parameterized economy analyzed here, this mechanism dominates the exect of a lower opportunity costs of time. A lower frequency of technology adoptions increases the average age of technology and reduces aggregate productivity. Hence, in the calibrated model, cross-country variation in investment distortions creates a positive correlation between output per capita and educational attainment, and a negative correlation with the age of the machines in operation.

Under the neutrality hypothesis, the prediction for the correlation output-years of schooling is the opposite. Section 3.2.2 showed that, much like under the learning assumption, the higher cost of equipment reduces the frequency of technology upgrades. 
Thus education, to the extent that it contributes to reduce the perceived cost of adoptions (through the term $1 / /=h$ ), becomes less valuabl e which tends to shorten the optimal school ing period. But in this economy, this exect is too weak as compared with the response to the reduction in the opportunity cost of schooling time.

The exect of changes in measures of the exectiveness of schools is illustrated in table 3.

\section{INSERT TABLE 3 ABOUT HERE}

Under the learning hypothesis for education, dixerences in , predict a negative association between educational attainment and output. In this economy, a lower, leads to a reduction in the opportunity cost of schooling time that overwhelms the other exects discussed in section 3.2.1. In particular, it is true that the induced rise in $\mathrm{m}$ tends to reduce the value of education, but in this case this exect is too weak.

Under the neutrality view of education, as discussed in section 3.2.2, a reduction in reduces the direct marginal return of education as well as the indirect return from reducing the exective cost of technology adoption $1 / 4 h$. These creates incentives for shorter schooling that dominate the response to a lower opportunity costs of schooling time. Thus lower exectiveness of schools reduces schooling and output per capita. In addition, it increases the ex ective adoption cost, $1 / \mathrm{h} h(\mathrm{~s})$, thereby raising the average age of capital and reducing output per capita further.

\subsubsection{Type-2 equilibrium}

With these parameters, type 2 equilibria are associated with a lower interest rate than type-1 equilibria. Hence the model produces higher levels of investment in education and output. Comparisons of type 2 balanced growth equilibria arising from dixerences in $1 / 4$, and - under the two assumptions on the role of education lead to exactly the same type of conclusions as for type 1 equilibria. Tables 4 and 5 report the results of the computations for type-2 equilibria under the parameters in table 1 . The two scenarios that deliver plausible correlations between output, educational attainment and the age of capital are the same as when comparing type-1 steady-states in section 5.2.1. 


\subsection{Robustness and Extensions}

With parameters calibrated to the type-2 steady-state, the qualitative ..ndings remain the same. Also, the nature of the results seems robust to alternative parameterizations and interpretations of parameters within the model. Concerning the latter, the interpretation of ${ }^{1}{ }_{0}$ and $h_{0}$ as measures of the exectiveness of schools leads to the same results. However, the model itself contains simplifying assumptions that at this stage deserve to be examined more carefully. The .rst is the assumption on the distribution of wealth as expressed in equation (18). The second is the assumption of learning as a discrete process. In the remaining of this section, I will examine alternative assumptions and demonstrate that the results derived so far remain largely intact.

\subsubsection{The distribution of wealth}

A $n$ alternative to (18) is the more natural assumption that an agent's lifetime wealth, $Z(i)$, consists of the value of the ..rm he or she operates. This amounts to replace (18) by the following,

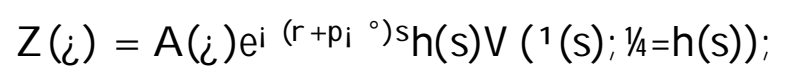

where the notation is the same as in problem (12). The equilibrium conditions apply to this case. Furthermore, a modest amount of work shows that, under the assumption on the distribution of wealth contained in (20), the characterization of balanced-growth equilibria is similar to that provided in proposition 4. As in that proposition, $r={ }^{\circ}$ is an equilibrium. Thus the type 2 equilibrium characterizes a balanced-growth path ir respective of the wealth distribution. Moreover, for all the economies analyzed under the assumption in (20), I have found that there is another equilibrium that, in terms of the value of $r$ relative to the one in the type-2 equilibrium, resembles the type-1 equilibrium of proposition 4. However, dixerently from the type-1 equilibrium under assumption (18), when (20) holds the interest rate cannot be characterized analytically and, in general, will change when parameters of the model change. Hence in this economy there will be richer general equilibrium exects from changes in $1 / 4$, or ${ }^{-}$. I study the scope of these new exects for economies that 
have the benchmark parameters in table 1 under the learning hypothesis. For the sake of comparability, for the neutrality hypothesis I have adjusted ${ }^{-}=0: 425$ and $h_{0}=0: 38$. N ow computing equilibria requires an additional round of iterations on the interest rate.

The results of the experiments for type-1 equilibria under (20) are illustrated in tables 6 and 7. The signs of the correlations do not dixer from the ones found with a constant interest rate. The model also delivers predictions for the correlation between output and the interest rate. This correlation is negative except for the changes in the school parameter under the neutrality assumption.

\section{INSERT TABLES 6 and 7 ABOUT HERE}

\subsubsection{Continuous learning}

A ssume learning-by-doing is a smooth function of time. In particular, let technology-sp eci..c skill, $q(m)$, be governed by the following version of the learning curve in Parente (1994),

$$
q(m)= \pm i( \pm i \quad 1) e^{i^{1} m}
$$

where \pm still represents the progress-ratio and ${ }^{1}$ measures the speed of learning. I maintain the other assumptions of the model. In this case, propositions 1 and 2 still hold and the solution to the adoption problem is the unique solution to a smooth ..rst order condition. Dixerently from the case with discreet learning, now the qualitative exect of ${ }^{1}$ on the optimal frequency of adoptions is ambiguous. The same arguments as before lead to the two balanced-growth path equilibria in proposition 4. I choose the analogous to equation (2) to be speci..ed as ${ }^{1}(\mathrm{~s})={ }^{1}{ }_{0} \mathrm{~s}$. I calibrate this model to the same targets as the discreet-learning model for the type-1 equilibrium. This results in exactly the same values for parameters other than those of the schooling technology in table 1. The parameters of the schooling technology that dixer from those in table 1 are as follows. Under the learning hypothesis, ${ }^{1}{ }_{0}=1: 4566 f 10^{i}{ }^{9}$ and $=9: 0$. Under the neutrality hypothesis ${ }^{1}{ }_{0}=1: 4566$.

F igures for comparisons of balanced-growth paths for dixerent $1 / 4$, and - are displayed in tables 8 and 9. They are virtually identical to those for the model with learning as a step function in tables 2 and 3. 


\subsection{Discussion.}

A theory of cross-country disparities must be consistent with the fact that richer countries tend to be more educated and use more advanced technologies. Under the learning assumption of education, it is found that cross-country disparity caused by variation in the size of investment distortions (but not in school exectiveness) is consistent with a positive association between output per-capita and the level of educational attainment. Under the neutrality hypothesis, variation in school exectiveness (but not in investment distortions) has implications consistent with these relationships. Furthermore, under these two scenarios, the average age of technologies in operation declines with the level of income per capita.

These results therefore illustrate the possible conłicting implications of dixerent assumptions on the role of education. A relevant question at this stage is to decide which of the two assumptions considered here is more reasonable. The learning hypothesis is explicit about the sort of skills provided by education and has been invoked in a number of empirical studies such as Welch (1970), Bartel and Litchenberg (1987), Foster and Rosenzweig (1996) and Rosenzweig (1995). In addition, this view can be rationalized, as Rosenzweig (1995) does, in the context of the information-theoretic model of learning in J ovanovic and Nyarko (1996). This approach creates a link between technology and the returns to schooling, and this paper has formalized this link and the analysis of its implications. The analysis of technology adoption proves to be essential to the argument.

On its part, what I have called the neutrality hypothesis, however, appears to be less explicit about what the skills involved are and where they come from. In this view, the connection between technology and the returns to schooling is weaker and plays just a supportive role. In other words, the predictions for schooling and output in a model that ignores the technology adoption problem -formally, with $\mathrm{V}(1 ; 1 / 4 \mathrm{~h})$ replaced by a constant in problem (12)- would be essentially the same.

All this notwithstanding, this paper cannot discriminate the two explanations of disparities across countries as the level exects associated with dixerences in school ing exectiveness 
and investment distortions are small under the two assumptions. This is not surprising for the case of changes in investment distortions under the learning hypothesis. In this model, like in J ovanovic and Rob (1998) and Parente (1999), dixerences in the age distribution of technologies alone can not produce wide dixerences in income per capita. Only large dixerences in speeds of learning-by-doing coupled with a large learning ratio can amplify the exects. However, the response of education in the model seems unable to bring about sizeable dixerences in the speed of learning and thereby in output even when large progress ratios are considered.

The quantitative properties of the model are surely related to its implications for the returns to schooling. For the benchmark economy, the return to one more year of education under the neutrality assumption is around 4 per cent for the type-1 equilibrium ${ }^{16}$. Under the learning assumption, the ..gure lies between 3.4-6.7 per cent. Bils and Klenow (1998) document an average Mincerian return to schooling of 9.9 per cent on a sample of 52 countries. Hence the calibration of the present model seems to grossly underestimate the return to education. This is more so for the type-2 equilibrium where the interest rate is particularly low.

\section{Conclusion and Final Remarks.}

This paper integrates the analysis of choices on education and on technology adoption to study international disparities. The analysis is conducted in a vintage capital model with technology speci..c learning-by-doing. Unlike previous studies, this allows to evaluate the importance of distortions that axect the cost of technology adoption and the exectiveness of education by testing their implications for output per capita, educational attainment, and the age of technologies in use. Remarkably, the analysis of technology adoption allows to consider alternative assumptions on the role of education.

The ..ndings for a reasonably parameterized version of the model are as follows. If the role of education is to improve the ability to learn technologies, only dixerences in the cost of technology adoption produce consistent correlations. On the other hand, if the role of education is to provide an absolute productive advantage that is independent of learning, then only dixerences in school exectiveness produce consistent correlations.

T wo main conclusions emerge from the analysis of this paper. First, predictions that 
can be obtained under supposedly simplifying assumptions on the role of education -such as the neutrality hypothesis- may dixer dramatically from the predictions derived under other less-simplifying assumptions -such as the learning hypothesis. Second, in the model analyzed changes in dixerent factors yield dixerent qualitative predictions. These dix ering implications can potentially be used to asses the importance of dixerent factors in devel opment. However, the present paper stands far on the way to drawing stronger conclusions in this sense. Not the least of the reasons is that the model's quantitative predictions do not accord with the data.

Directions for further research involve natural extensions of the present framework. The model contains assumptions that impose tight bounds on the size of the dixerences in income that can be produced. Notably, all agents adopt the frontier technology and learning is completely technology-speci..c. I think that a model analyzing the transmission of knowledge across technologies, rather than uniquely its accumulation within each single technology, oxers reasonable expectations of better matching the data. In such a framework, the mechanisms analyzed here would still play an important role. 


\section{R eferences}

[1] Bahk, B. and Gort, M. (1993), "Decomposing Learning by Doing in New Plants", J ournal of Political Economy, 101, 561-583.

[2] Barro, R. J . and Lee, J -W . (1993), "International Comparisons of Educational Attainment", J ournal of M onetary Economics, 32, 363-394.

[3] Barro, R. J . and Lee, J -W . (1994), "Sources of E conomic G rowth", Carnegie-R ochester Conference Series on P ublic P olicy, 40, 1-46.

[4] Barro, R. J . and Lee, J -W . (1997), "Schooling Quality in a Cross-Section of Countries", NBER W orking Paper No. 6198.

[5] Bartel, A. P. and Litchtenberg F . R . (1987), "The Comparative A dvantage of E ducated Workers in I mplementing New Technology", The R eview of E conomics and Statistics, 69, 1-11.

[6] Bessen, J . (1997), "P roductivity A djustments and Learning-by-Doing as Human Capital", Mimeo.

[7] Bils, M. and Klenow P. J. (1998), "Does Schooling Cause Growth or the Other Way A round?" NBER Working Paper No. 6393.

[8] Chari, V., Kehoe, P. and McGrattan, E. (1997), "The Poverty of Nations: a Quantitative Investigation", Fed Minneapolis Research Department Staø Report 204.

[9] Ciccone, A. (1996), "Rapid Catch-Up, Fast Convergence and Persistent Underdevelopment", Mimeo.

[10] Cooley, T . F ., G reenwood, J . and Yorukoglu, M . (1997), "T he R eplacement Problem", J ournal of Monetary Economics, 40, 457-499.

[11] Foster, A. D. and R osenzweig, M. R. (1996), "Technical Change and Human Capital R eturns and I nvestments: Evidence from the G reen Revolution", American E conomic Review, 86, 931-953.

[12] Greenwood, J. and Yorukoglu, M. (1996), "1974", Rochester Center for E conomic Research W orking Paper No. 429.

[13] Grossman, G. M. and Helpman, E. (1991) Innovation and Growth in the Global E conomy, MIT P ress.

[14] Hendricks, L. (1997), "Equipment Investment and Growth in Developing Countries", Mimeo.

[15] J ones, C. I. (1994), "E conomic Growth and the Relative Price of Capital", J ournal of Monetary Economics, 34, 359-382.

[16] J ovanovic, B. (1998), "V intage Capital and Inequality", Review of Economic Dynamics, $1,497-530$.

[17] J ovanovic, B. and Rob, R. (1998), "Solow vs Solow", Mimeo. 
[18] J ovanovic, B . and Nyarko, Y . (1996), "Learning-by-D oing and the Choice of Technology", E conometrica, 64, 1299-1310.

[19] J ovanovic, B . and Nyarko, Y . (1995), "A B ayesian Learning M odel Fitted to a Variety of Empirical Learning Curves", Brooking Papers of Economic Activity, Microeconomics, 245-300.

[20] Keller, W. (1996), "A bsorptive Capacity: on the Creation and A cquisition of Technology in Development", J ournal of Economic Development, 49, 199-227.

[21] K lenow, P. J . (1998), "Learning Curves and the Cyclical Behavior of M anufacturing Industries", Review of Economic Dynamics, 1, 531-550.

[22] Lucas, R. E. (1988), "On the M echanics of E conomic Development", J ournal of M onetary E conomics, 22, 3-42.

[23] Nelson, R. and Phelps, E. (1966), "Investments in Humans, Technological Dixusion, and Economic Growth", American Economic Review, Papers and Proceedings, 61, 69-75.

[24] Parente, S. L. (1999), "Learning-by-U sing and the Switch to Better Machines", Mimeo,.

[25] Parente, S. L. (1994), "Technology A doption, Learning-by-Doing and Economic Growth", J ournal of Economic Theory, 63, 346-369.

[26] Parente, S. L. and Prescott, E.C. (1994), "Barriers to Technology A doption and Development", J ournal of Political Economy, 102, 298-321.

[27] Rapping, L. A . (1965), "Learning and World War II Production Functions", Review of E conomics and Statistics, 47, 81-86.

[28] Restuccia, D. (1997), "Technology Adoption and Schooling", Mimeo.

[29] Rosenzweig, M. R. (1995), "Why A re There Returns to Schooling?", American Economic Review, Papers and Proceedings, 85, 151-158.

[30] Schultz, T. W. (1975), "The Value of the A bility to Deal with Disequilibria", J ournal of E conomic Literature, 13, 827-846.

[31] Stokey, N. L. (1991), "Human Capital, Product Quality, and Growth", Quarterly J ournal of Economics, 106, 587-616.

[32] Summers, R. and Heston, A. (1991), "The Penn World Table (Mark 5): an Expanded Set of International Comparisons", Quarterly J ournal of Economics, 106, 327-368.

[33] Welch, F. (1970), "E ducation in Production", J our nal of P olitical E conomy, 78, 35-59.

[34] Wolx, E. (1991), "Capital Formation and Productivity Convergence Over the LongTerm", American E conomic Review, 81, 565-579. 


\section{A ppendix: Proof of Propositions 1 Through 3.}

Proof of proposition 1: C1 implies that the solution is a feasible adoption plan $\left(\mathrm{J} ; \mathrm{f} \mathrm{x}_{\mathrm{j}} \mathrm{g} ; \mathrm{a}(\mathrm{t} ; \mathrm{i})\right)$ since a feasible adoption plan with $\mathrm{J}=1$ exists where the expression in (7) has a positive value.

I will now prove that in an optimal plan $W\left(m_{j}\right)>0$ for all $j=1 ; 2 ;: .: ;$ J . In an optimal adoption plan $W\left(m_{j}\right)>0$ for some $j$. Then $W\left(m_{1}\right)>0$ since, otherwise, the value in (7) would increase by holding on until $x_{1}=x_{j}$. Finally, assume that, for some $\mathrm{j}$ in an optimal plan, $\mathrm{W}\left(\mathrm{m}_{\mathrm{j}}\right) \quad 0$. Since $\mathrm{W}(\mathrm{:})$ is monotonically increasing, the value in (7) would increase by holding out the $\mathrm{j} i$ 1th adoption until $x_{j+1}$. But then $x_{j}$ cannot be the $j$ th adoption which contradicts the optimality of the plan containing $x_{j}$.

Now part (a) follows from inspection of (7). To prove part (b), use that $A\left(x_{j}\right)=$ $A(i+s) \exp \left({ }^{\circ}\left(x_{j} i(z+s)\right)\right)$ to rewrite $(7)$ as

$$
\begin{aligned}
& h \phi A(i+s) \pitchfork_{j=1}^{X} W\left(x_{j+1} i \quad x_{j}\right) e^{i\left(r+p_{i}{ }^{\circ}\right)\left(x_{j i}(i+s)\right)} \\
= & h \phi A(i+s) \phi_{j=1}^{X} W\left(m_{j}\right) e^{i\left(r+p_{i}{ }^{\circ}\right)\left(x_{1}+P_{i=1}^{P} m_{i} i(i+s)\right)}
\end{aligned}
$$

where the equality follows from the notation $m_{j}$ ' $x_{j+1} i x_{j}$. Therefore, for any given sequence of tenures $f m_{j} g$, by anticipating the start of production [i.e. reducing $x_{1}$ ] the value of (7) increases unambiguously by assumption $C 2$. That $i+\mathrm{s}$ is the earliest feasible starting date concludes.Q.E.D.

Proof of proposition 2: The results in Proposition 1 imply that (7) can be written as

$$
h \Phi A(i+s) \nsubseteq V\left(f m_{j} g_{j=1}\right)
$$

with

$$
V\left(f m_{j} g_{j=k}\right)^{\prime}{ }_{j=k}^{X} W\left(m_{j}\right) e^{i\left(r+p_{i}{ }^{\circ}\right)}{ }_{\substack{j i 1 \\ i=k}} m_{i}:
$$

So the problem is to choose $J$ and $f m_{j} g$ that maximize $V\left(f m_{j} g_{j=1}\right)$. The 
objective can be written recursively as

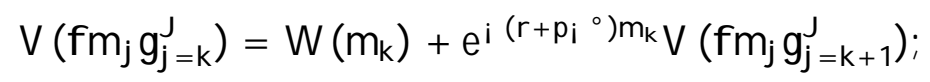

for $k=1 ; 2 ;:: ; j$. L Let $V_{k}{ }^{\prime} \max V\left(f m_{j} g_{j=k}\right)$. Since the value $V\left(f m_{j} g_{j=k}\right)$ only depends on the sequence of tenures, the solution must be the same value $V=V_{k}$ for all k. Hence the problem is equival ent to solving (8). Expression (9) follows from the de..nitions.Q.E.D.

Proof proposition 3: To simplify notation, let $D(m) ' e^{i\left(r+p_{i}{ }^{\circ}\right) m}$. At points $m \sigma^{1}$ the derivative of the objective in (8) is given by $\left.\left.W 9 m\right)+D 9 m\right) \frac{W(m)}{l_{i} D(m)}$. By (8), at the optimum, $V=W(m) \neq 1 ; D(m))$ and this derivative is given by the left-hand side of $(10)$ denoted by $₫(\mathrm{~m})$.

It is helpful to write $\pitchfork(\mathrm{m})$ as

$$
W^{9}(m)+D^{9}(m) \frac{W(m)}{1 i \quad D(m)}=e^{i(r+p) m} i(m)
$$

where

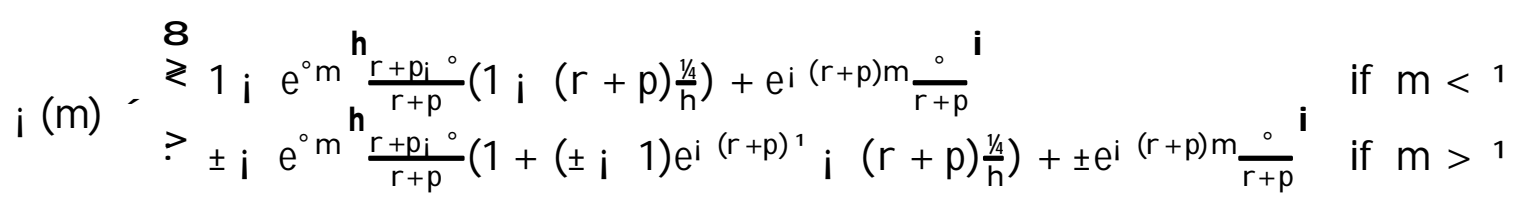

Thus I can analyze the shape of $\phi(m)$ in (10) by analyzing $\mathrm{i}(\mathrm{m})$.

a. By $\mathrm{C} 1$ and $\mathrm{C} 2$ it follows that $\mathrm{i}(+1)<0$ which rules out the optimality of $m=+1$.

By C2, i (0) >0 which rules out $m=0$. C2 also implies $\lim _{1}+\mathrm{i}(\mathrm{m})>$ $\lim _{1_{i}} i(m)$ which rules out optimality of $m=1$ where $i(:)$ is non dixerentiable. A ny local extremum must then satisfy $\mathrm{i}(\mathrm{m})=0$.

b. A little al gebra shows that in either region, $m<^{1}$ or $m>^{1}$, there can be at most one root of $\mathrm{i}(\mathrm{m})=0$. This follows from the fact that, if for some $m$ i $(m)$ is decreasing, then it is so for any larger $m$ in either region.

It is useful to state this as a lemma. 
Lemma 1: Let $\mathrm{m}$ and $\mathrm{m}^{0}$ belong to either $\left(0 ;{ }^{1}\right)$ or $\left({ }^{1} ; 1\right)$. Assume $m^{0}>m$. Then if $\left.i 9 m\right)<0$, then $i 9 m 9<0$. If $i(m)=0$, then $\mathrm{m}$ is a local maximum.

Now I will take the dixerent cases in turns.

- Case $\lim _{1} i(m)>0$. By C2 one .nds $i(0)>0$ and $\left.i 90\right)>0$. Then, by Lemma $1, \lim _{1 i} i(m)>0$ implies that $i(m)>0$ all $m<1$. Thus there is no $m<1$ such that $i(m)=0$.

By C2 it follows that $\lim _{1 i} i(m)<\lim _{1+i}(m)$. Then $\lim _{1_{i}} i(m)>0$ implies $\lim _{1+} i(m)>0$. Now $C 1$ and $C 2$ imply $i(1)<0$ and then there exists an $m>1$ such that $i(m)=0$. Lemma 1 concludes establishing this is unique and the maximum.

- Caselimi ${ }_{1} i(m)<0$ and $\lim _{1+i}(m)<0$. C2 implies $i(0)>0$. Then $\lim _{1 i} i(m)<0$ and Lemma 1 implies that there is a single $m<1$ such that $i(m)=0$ which is a local maximum.

It is a fact that $\left.\left.\lim _{1} ; 9 m\right)=\lim _{1+i} 9 m\right)$. Since Lemma 1 implies $\lim _{1,} i^{9}(m)<0$, it follows that $\lim _{1+} i^{9}(m)<0$. Now the assumption that $\lim _{1+i}(m)<0$ implies that $i(m)<0$ all $m>1$. Part a of this proposition then concludes that the maximum is the $m<1$ such that $i(m)=0$.

- Case $\lim _{1_{i}} \mathrm{i}(\mathrm{m})<0$ and $\lim _{1+} \mathrm{i}(\mathrm{m})>0$.

As in the previous case there exists one $m<1$ such that $i(m)=0$. Similarly, using that $\mathrm{C} 1$ and $\mathrm{C} 2$ imply $\mathrm{i}(+1)<0$, there is also a local maximum $m>1$. By (8), at the solution $V=W(m)=(1 ; D(m))$. This concludes the proof.

Q.E.D. 


\section{Footnotes}

${ }^{1}$ In 1960, years of schooling averaged 1.39 in the poorest third of countries, 2.91 in the middle third of countries, and 5.6 in the top third group of countries. The ..gures for 1985 are 2.18, 4.67 and 7.94 years of schooling respectively. The ..gures for years of schooling are calculated from B arro and Lee (1993). Countries have been ranked according to ..gures on GDP per capita in Summers and Heston (1991) Mark 5.0.

2 There are not aggregate measures of the age of capital available for a large set of countries. For the more devel oped economies, the ..gures reported in W olf (1991) show that changes in economic leadership over the last century are related to changes in dominance in new capital vintages. On the other hand, there is microeconomic evidence- for example, Welch (1970), Bartel and Litchenberg (1987), and Foster and Rosenzweig (1996)- that education axects the choice of technology.

3 This is a simpli..cation with respect to Parente (1994) and J ovanovic and Nyarko (1996) who allow for dixerent degrees of transferability of knowledge across vintages. In terms of J ovanovic and Nyarko, I am in case ${ }^{\circledR}=0$ (in their equation (3)).

4 Rosenzweig (1995) identi..es two roles of education in J ovanovic and Nyarko (1996)'s Bayesian learning target-input model. First, the more educated may obtain more information from each use of the technology as refected in a lower variance of the optimal target which speeds up the gain in the precision of optimal decisions. This is similar to my learning hypothesis that education lowers ${ }^{1}$. Second, education may also improve access to information sources as rełected in a lower variance of the prior about the input target which improves the initial precision of decisions in a new technology. This information prior assumption does not correspond to my neutrality hypothesis. It would be picked up in my model by letting education raise $h$ - just like under the neutrality assumption- and, in addition, replacing \pm by $\pm=h$. Intuitively, if the initial productivity in a new technology is higher, then the gain from experience is smaller for given full-potential productivity $a \pm$

I think that my neutrality assumption could be accommodated in a version of J ovanovic and Nyarko's information setup where the posterior variance is bounded above zero (possibly introducing an additional source of noise) and education reduces this lower bound as well as the prior variance. To my knowledge, this sort of analysis has not yet been carried out and I have to accept that this hypothesis is less wel founded on an information-theoretic 
model but seems to capture the practice in part of the literature on human capital.

${ }^{5} \mathrm{~T}$ his is a simplifying assumption that facilitates exposition. A nother possible assumption is that an agent's wealth is given by the present value of the ..rm he or she operates. Section 5 shows that this more natural assumption has no substantive exect.

${ }^{6}$ With $\mathrm{C} 1$ but not $\mathrm{C} 2$, it is optimal to wait in..nity to start producing. Without $\mathrm{C} 1$, it is optimal to produce zero. Propositions 1, 2 and 3 are proved in appendix A

${ }^{7} \mathrm{~T}$ he discussion that foll ows relies on the following derivation. Usetheenvel ope theorem [i.e. Eq.(11)] to show that the ..rst left-hand side term in (13) can be written as,

$$
\frac{d V(1(s) ; 1 / 4 h)}{d^{1}}=\frac{(1=(r+p))\left[i( \pm i \quad 1)(r+p) e^{i(r+p)^{1}(s)}\right]}{1 i e^{i\left(r+p^{\circ}\right) m}}
$$

8 If lower school exectiveness is represented by larger ${ }^{1}{ }_{0}$ rather than smaller, , then $\mathrm{i}^{10}{ }^{0}$ goes up which works for larger $\mathrm{S}$.

${ }^{9}$ For the discussion that follows it is useful to calculate

$$
i \frac{d V}{d(1 / / h h)} 1 / \frac{h^{0}}{h}=h^{0} \frac{1}{1 i e^{i\left(r+p_{i}{ }^{\circ}\right) m} \frac{1 / 4}{h}+V(1 / 4 h)}
$$

Then the derivative of this expression with respect to $1 / 4$ is

$$
h \frac{0^{1 / 4}}{h} \frac{i\left(r+p i^{\circ}\right)}{1 e^{i\left(r+p_{i}^{\circ}\right) m}} \frac{d m}{d^{1 / 4}}<0
$$

${ }^{10}$ If $\mathrm{V}$ did not depend on $\mathrm{h}$, then the two exects would exactly cancel out.

${ }^{11} \mathrm{~T}$ he demographic assumptions made imply that $p \exp (\mathrm{i} \mathrm{pu})$ is the size of population aged $u$. Therefore the measure of individuals adopting the frontier technology at any instant along a balanced-growth path is $p \exp (i p s)+p \exp (i p(s+m))+p \exp (i p(s+$ $2 m))+p \exp (i p(s+3 m))+:::=[p \exp (i p s)]=[1 ; \exp (i p m)]$. Investment is this number times the cost of a new machine $1 / \mathrm{A}(\mathrm{t})$.

12 The average age of machines is computed as $\left(1=^{\circ}\right) \log (A(t)=\bar{A}(t))$ with $\bar{A}(t)=$ $A(t)\left(p=\left(^{\circ}+p\right)\right)\left(1 ; \exp \left({ }^{\circ}+p\right) m\right)=(1 ; \exp (i p m))$.

${ }^{13} \mathrm{R}$ apping (1965) found a 40 percent yearly productivity growth in US ship-building yards over 1941-1944. These ..gures suggest a lower bound for the progress ratio around 3.3. J ovanovic and Nyarko (1995) ..t learning curves to productivity data on a number of new activities. The data they use include progress ratios ranging from 111 to 3 , but for many 
activities more modest learning rates are found. Other studies seem to suggest that progress ratios are generally of the order or several percentage points only, much smaller than the several-fold gains found in case studies. In Bahk and Gort (1993) the total productivity gain is around 15 percent for recently-born plants (average 1 per cent per year over 14 years). On a sample of new plant start-ups in US manufacturing industries, Bessen (1997) estimates an average progress ratio after learning is exhausted ( 5 years) of 5.7 per cent.

A s B essen (1997) points out, the case study literature shows that most of productivity gains from learning occur initially over a short span of time. Thus low frequency data and the loss of information on initial months of activity may explain why some studies- such as Bahk and Gort (1993)- tend to underestimate the measures of learning or, in other words, to overestimate initial productivity.

${ }^{14}$ As mentioned in footnote 13 , it seems that most learning accrues during the ..rst few months of an activity. Bessen (1997) argues that assuming that, on average, reported annual data drops the ..rst 6 months of activity helps to reconcile the dixering ..ndings across empirical studies on learning. The continuous-learning approximation to the current calibration implies a half-life of 0.47 , which means that after the ..rst 6 months of activity about a 30 per cent increase in productivity is left to be learnt. This is more in line with the industry ..gures found in Bahk and Gort (1993) and Bessen (1997).

Parente (1999) assumes a larger progress ratio and a somehow higher speed of learning. 15 In other words ,

$$
W(m)={ }_{0}^{Z} e^{i(r+p) t}\left[2 ; \quad(2 ; 1) e^{i: 4565 t}\right] d t ; \frac{1 / 4}{h^{\prime}}
$$

where $m$ is the model's optimal time between adoptions and $W(m)$ is as in equation (6) with $\pm=2$.

${ }^{16} \mathrm{~T}$ his number has been calculated numerically from the impact on aggregate output per ..rm of changing s exogenously from 9 to 10 and from 10 to 11 . It is close to the percentage change in $h,-\rightarrow$, thus suggesting that the exect of education on output through $1 / 4 h$ is small in the margin. 


\begin{tabular}{|ll|ll|}
\hline \multicolumn{4}{|c|}{ Table 1: Benchmark E conomy } \\
\hline & & Learning hypothesis & Neutrality hypothesis \\
$3 / 4=1: 25$ & $1 / 2=0: 02$ & ${ }_{1}=5000$ & ${ }_{0}=0: 6728$ \\
$0=0: 02$ & $p=0: 015$ & $.=0: 8914$ & $,=0: 0$ \\
$\pm=2: 0$ & $1 / 4=1: 12$ & $h_{0}=1: 0$ & $h_{0}=0: 43$ \\
& & $-=0: 0$ & $-=0: 37$ \\
\hline
\end{tabular}




\begin{tabular}{|c|c|c|c|c|c|c|c|c|}
\hline Investment distortions & \multicolumn{4}{|c|}{ Learning hyp othesis } & \multicolumn{4}{|c|}{ Neutrality hypothesis } \\
\hline $1 / 4$ & $\bar{s}$ & $\mathrm{~m}$ & $y=y \cup s$ & age & $\bar{s}$ & $m$ & $y=y$ us & \\
\hline 1.12 & 10.0 & 10.85 & 1.0 & 5.18 & 10.0 & 10.85 & 1.0 & 5.18 \\
\hline 1.72 & 9.9 & 13.06 & 0.987 & 6.17 & 10.3 & 12.81 & 1.0 & 6.06 \\
\hline 2.32 & 9.8 & 15.11 & 0.973 & 7.08 & 10.5 & 14.61 & 0.987 & 6.86 \\
\hline 2.92 & 9.8 & 16.86 & 0.960 & 7.84 & 10.8 & 16.26 & 0.979 & 7.58 \\
\hline 3.52 & 9.7 & 18.74 & 0.946 & 8.64 & 11.0 & 17.85 & 0.973 & 8.27 \\
\hline
\end{tabular}

\begin{tabular}{|c|c|c|c|c|c|c|c|c|c|}
\hline \multicolumn{4}{|c|}{ Table 3. Type-1 equilibrium. Changes in school exectiveness } & & \multirow{2}{*}{$\begin{array}{c}\text { E xectiveness } \\
- \\
0.37\end{array}$} & \multicolumn{4}{|c|}{ "Neutrality hypothesis } \\
\hline 0.89 & & $\begin{array}{l}\mathrm{m} \\
1085\end{array}$ & $\begin{array}{l}y=y \text { us } \\
10\end{array}$ & $\begin{array}{l}\text { age } \\
5,18\end{array}$ & & & $\begin{array}{l}\mathrm{m} \\
1085\end{array}$ & $\begin{array}{l}y=y \text { us } \\
10\end{array}$ & $\begin{array}{l}\text { age } \\
5.18\end{array}$ \\
\hline 0.78 & 11.3 & 11.16 & 0.979 & 5.32 & 0.27 & 7.40 & 12.47 & 0.758 & 5.81 \\
\hline 0.70 & 12.3 & 11.58 & 0.953 & 5.51 & 0.17 & 4.80 & 13.79 & 0.591 & 6.50 \\
\hline 0.59 & 14.3 & 12.28 & 0.913 & 5.83 & 0.07 & 2.0 & 15.27 & 0.490 & 7.15 \\
\hline
\end{tabular}




\begin{tabular}{|c|c|c|c|c|c|c|c|c|}
\hline \multicolumn{9}{|c|}{ Table 4. Type-2 equilibrium. Changes in investment distortions } \\
\hline$\overline{\text { Investment distortions }}$ & \multicolumn{4}{|c|}{ Learning hyp othesis } & \multicolumn{4}{|c|}{ Neutrality hypothesis } \\
\hline $\begin{array}{r}1 / 4 \\
112\end{array}$ & & $\begin{array}{l}m \\
9.15\end{array}$ & $y=y$ us & $\begin{array}{l}\text { age } \\
4.40\end{array}$ & $\begin{array}{l}5 \\
260\end{array}$ & $\begin{array}{l}m \\
9>6\end{array}$ & $y=y$ us & $\begin{array}{l}\text { age } \\
445\end{array}$ \\
\hline 1.72 & 10.9 & 11.11 & 0.980 & 5.30 & 26.5 & 10.63 & 0.994 & 5.08 \\
\hline 2.32 & 10.9 & 12.85 & 0.967 & 6.08 & 27.0 & 11.86 & 0.982 & 5.64 \\
\hline 2.92 & 10.8 & 14.52 & 0.954 & 6.82 & 27.4 & 13.00 & 0.976 & 6.15 \\
\hline 3.52 & 10.7 & 16.08 & 0.941 & 7.50 & 27.8 & 14.07 & 0.964 & 6.63 \\
\hline
\end{tabular}

\begin{tabular}{|c|llll||c|llll|}
\hline \multicolumn{8}{|c|}{ Table 5. Type-2 equilibrium. Changes in school exectiveness } \\
\hline \hline Exectiveness & Learning hyp othesis & Exectiveness & \multicolumn{4}{|c|}{ Neutrality hypothesis } \\
\hline 0.89 & $\mathrm{~s}$ & $\mathrm{~m}$ & $\mathrm{y}=\mathrm{y}$ us & age & & $\mathrm{s}$ & $\mathrm{m}$ & $\mathrm{y}=\mathrm{y}$ us & age \\
0.78 & 11.20 & 8.90 & 1.00 & 4.29 & 0.37 & 24.90 & 9.31 & 1.00 & 4.47 \\
0.70 & 12.60 & 9.07 & 0.974 & 4.36 & 0.27 & 19.30 & 10.57 & 0.734 & 5.05 \\
0.59 & 13.80 & 9.19 & 0.954 & 4.42 & 0.17 & 12.40 & 12.16 & 0.556 & 5.77 \\
\hline
\end{tabular}




\begin{tabular}{|c|c|c|c|c|c|c|c|c|c|c|}
\hline$\overline{\text { Investment distortions }}$ & 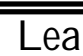 & $\overline{\overline{\text { ning h }}}$ & pothesi & & & Neut & $\overline{\text { ality } h}$ & pothes & & \\
\hline $1 / 4$ & $\mathrm{~s}$ & $\mathrm{~m}$ & $y=y$ us & age & $r \%$ & $\mathrm{~s}$ & $\mathrm{~m}$ & $y=y u s$ & age & $r \%$ \\
\hline 1.12 & 9.8 & 11.44 & 1.0 & 5.45 & 5.18 & 9.8 & 11.42 & 1.0 & 5.44 & 5.17 \\
\hline 1.72 & 9.7 & 13.71 & 0.986 & 6.46 & 5.18 & 10.1 & 13.40 & 1.0 & 6.33 & 5.20 \\
\hline 2.32 & 9.7 & 15.61 & 0.973 & 7.30 & 5.19 & 10.3 & 15.24 & 0.993 & 7.14 & 5.22 \\
\hline 2.92 & 9.6 & 17.66 & 0.960 & 8.18 & 5.20 & 10.5 & 16.98 & 0.986 & 7.89 & 5.24 \\
\hline 3.52 & 9.6 & 19.42 & 0.946 & 8.93 & 5.21 & 10.7 & 18.64 & 0.980 & 8.60 & 5.26 \\
\hline
\end{tabular}

\begin{tabular}{|c|c|c|c|c|c|c|c|c|c|c|c|}
\hline E rectiveness & \multicolumn{5}{|c|}{ Learning hypothesis } & \multirow{3}{*}{$\begin{array}{c}\text { Exectiveness } \\
0.42\end{array}$} & \multicolumn{5}{|c|}{ Neutrality hypothesis } \\
\hline & $\mathrm{s}$ & $\bar{m}$ & $y=y$ us & age & & & $\mathrm{s}$ & $\mathrm{m}$ & $y=y_{\text {US }}$ & & $r \%$ \\
\hline 0.89 & 9.8 & 11.44 & 1.0 & 5.45 & 5.18 & & 9.8 & 11.42 & 1.0 & 5.44 & 5.17 \\
\hline 0.78 & 11.0 & 11.98 & 0.973 & 5.6 & 5.24 & 0.33 & 7.8 & 12.76 & 0.756 & 6.04 & 5.06 \\
\hline 0.70 & 12.0 & 12.44 & 0.953 & 5.90 & 5.30 & 0.23 & 5.7 & 14.28 & 0.588 & 6.71 & 4.94 \\
\hline 0.63 & 13.2 & 13.05 & 0.919 & 6.17 & 5.36 & 0.13 & 3.4 & 15.86 & 0.475 & 7.41 & 4.80 \\
\hline
\end{tabular}




\begin{tabular}{|c|c|c|c|c|c|c|c|c|}
\hline Investment distortions & \multicolumn{4}{|c|}{ Learning hyp othesis } & \multicolumn{4}{|c|}{ "Neutrality hypothesis } \\
\hline $1 / 4$ & $\mathrm{~s}$ & $\mathrm{~m}$ & $y=y$ us & age & & $\mathrm{m}$ & $y=y$ us & age \\
\hline 1.12 & 10.0 & 10.85 & 1.0 & 5.18 & 10.0 & 10.85 & 1.0 & 5.18 \\
\hline 1.72 & 9.9 & 13.06 & 0.987 & 6.17 & 10.3 & 12.81 & 0.993 & 6.06 \\
\hline 2.32 & 9.8 & 15.12 & 0.973 & 7.08 & 10.5 & 14.61 & 0.987 & 6.86 \\
\hline 2.92 & 9.8 & 16.86 & 0.956 & 7.84 & 10.8 & 16.26 & 0.970 & 7.58 \\
\hline 3.52 & 9.7 & 18.74 & 0.946 & 8.64 & 10.9 & 17.34 & 0.973 & 8.05 \\
\hline
\end{tabular}

\begin{tabular}{|c|c|c|c|c|c|c|c|c|c|}
\hline Exectiveness & \multicolumn{4}{|c|}{ Learning hypothesis } & \multirow{2}{*}{$\begin{array}{c}\text { Exectiveness } \\
0.37\end{array}$} & \multicolumn{4}{|c|}{ Neutrality hypothesis } \\
\hline Q & $\mathrm{s}$ & $\mathrm{m}$ & $y=y$ us & age & & & & $y=y$ us & $\begin{array}{l}\text { age } \\
518\end{array}$ \\
\hline 8.56 & $\begin{array}{l}10.0 \\
11.0\end{array}$ & $\begin{array}{l}10.85 \\
11.36\end{array}$ & $\begin{array}{l}1.0 \\
0.980\end{array}$ & $\begin{array}{l}5.18 \\
5.41\end{array}$ & $\begin{array}{l}0.31 \\
0.27\end{array}$ & $\begin{array}{l}10.0 \\
7.40\end{array}$ & $\begin{array}{l}10.85 \\
12.25\end{array}$ & $\begin{array}{l}1.0 \\
0.756\end{array}$ & $\begin{array}{l}5.10 \\
5.81\end{array}$ \\
\hline 8.11 & 12.3 & 11.80 & 0.946 & 5.61 & 0.17 & 4.80 & 13.79 & 0.591 & 6.50 \\
\hline 7.44 & 14.6 & 13.17 & 0.886 & 6.22 & 0.07 & 2.00 & 15.27 & 0.490 & 7.15 \\
\hline
\end{tabular}

